\title{
Study on aluminum foam as a filler material for impact limiter of spent fuel transport cask
}

\author{
Zhongfang Li, Siyi Yang ${ }^{*}$, Haile Xu and Yukun An \\ School of Mechanical Engineer, Shandong University of Technology, Zibo, China
}

\begin{abstract}
Spent fuel transport cask is a significant carrier of spent fuel transport. The main function of impact limiters installed at both ends of the container is to absorb energy and limit overload to ensure the integrity of the structure. The quasi-static compression process of aluminum foam was simulated on the platform of ANSYS Workbench. Foam aluminum was prepared by melt foaming method and quasi static compression test was carried out. The experimental results show that the deformation process of aluminum foam is basically the same as that of experiment, and the aluminum foam has good compressive and energy absorption properties. The yield stress $\left(\sigma_{y s}\right)$ and plateau stress $\left(\sigma_{p l}\right)$ of aluminum foam with density of $0.64 \mathrm{~g} / \mathrm{cm}^{3}$ can reach $8.26 \mathrm{MPa}$ and $11.11 \mathrm{MPa}$ respectively, and the energy absorption capacity $\left(W_{E A}\right)$ and unit energy absorption capacity $\left(W_{S E A}\right)$ can reach $6.31 \times 10^{3} \mathrm{KJ} / \mathrm{m}^{3}$ and $9.87 \mathrm{KJ} / \mathrm{Kg}$ respectively, and the difference between the foam with density of $0.61 \mathrm{~g} / \mathrm{cm}^{3}$ and its various properties is very small. It can be concluded that the aluminum foam in a certain density range has roughly the same performance, and it also reflected the stability of aluminum foam's performance. Additionally, aluminum foam is an isotropic material, which can overcome directional limitation when used as shock absorber filler material for spent fuel transport cask.
\end{abstract}

\section{Introduction}

Spent fuel transport is the link between nuclear power plant and reprocessing plant or final disposal plant. It controls the continuous operation of both plants to a certain extent, and spent fuel transport cask is a significant carrier to achieving this process $[1,2]$. To ensure the integrity of the transport cask under normal transport and accident conditions, the International Atomic Energy Agency (IAEA) issued the "Regulations for the Safe Transport of Radioactive Materials"[3]. China had made GB11806 standards on this basis as well [4]. The transport cask should be tested through $9 \mathrm{~m}$ drop test, $1 \mathrm{~m}$ penetration test, $30 \mathrm{~min}$ fire $\left(800{ }^{\circ} \mathrm{C}\right)$ and $15 \mathrm{~m}$ flooding test. For the first test, the cask dropped freely onto an unyielding surface from $9 \mathrm{~m}$. Pair of impact limiters installed on the top and the bottom of a transport cask is the crucial safety component to absorb most of the impact energy and limit overload, which can ensure the integrity of the structure.

Over the years, many scholars have studied several of impact limiter filler materials. Zhou Y, You M and Zhang Y [2] designed and studied China's RY-I type spent fuel transport cask, in which paulownia wood was used for the first time to replace light wood as impact limiter filler material. Silva and Kyriakides [5] evaluated the compressive response and failure behavior of balsa wood based on its microstructure and found that the internal structure of balsa wood was composed of slender cells with similar hexagonal cross-sections that arranged axially. Choi and Seo [6] conducted dynamic impact experiments on polyurethane foam, honeycomb, and balsa wood respectively. The experimental results showed that balsa wood with the axial wood grain had the most significant absorbed energy.

As the drop mode of spent fuel transport cask under accident conditions was summarized as three types (Fig. 1): vertical drop, horizontal drop, and corner drop [6]. Wood, the main filler material at present, is restricted by directivity because it is an anisotropic material. In addition, due to the water absorption of wood and low ignition point, the influence of environmental factors would reduce the life of the impact limiter. Aluminum foam is an isotropic material with good compressive and energy absorption properties, which can ensure the integrity of the cask when three possible dropping modes occur. In this paper, the compression process of aluminum foam was simulated on the platform of ANSYS Workbench, and quasi-static compression experiment was designed on the basis of which the compression performance and energy absorption performance were verified.

Corresponding author: yangsiyichina@yeah.net (Siyi Yang) 


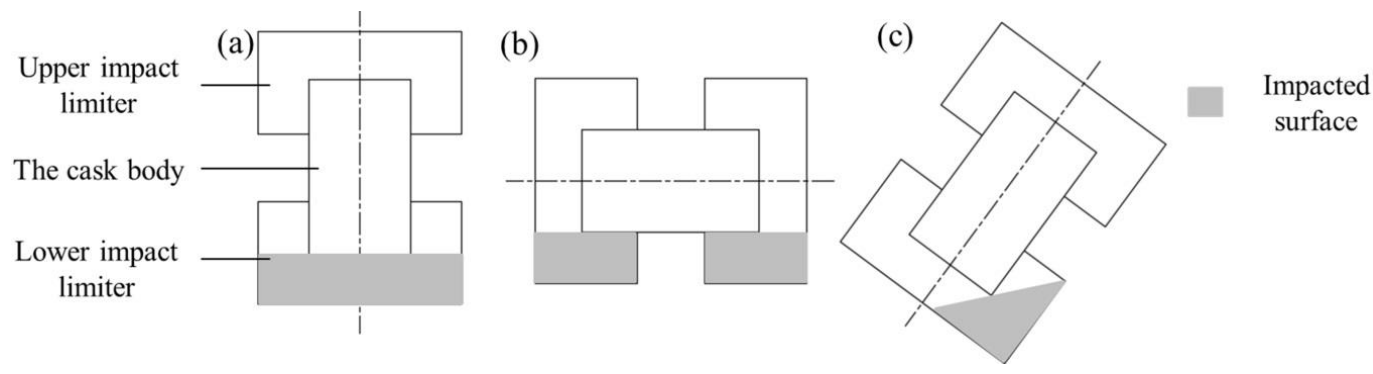

Figure 1. Dropping conditions of spent fuel transport container: (a) end drop; (b) corner drop; (c) side drop.

\section{Modeling and simulation}

\subsection{Preparation of aluminum foam model}

There are three main modeling methods for aluminum foam: repeated fixed pore structure (spatial lattice solid and beam structure) [7], randomly generated pore (2D circular pore and 3D Voronoi) [8] and physical scanning technology (CT scanning) [9]. Simulating foam materials with repeated fixed structure models have been common in the study of various foam materials [10]. The results of the large deformation compression simulation of the tetrahedron model of aluminum foam show that the stress-strain relationship of [10] begins to converge obviously after using 27 elements of $3 \times 3 \times 3$, so it is unnecessary to use more repetitive structures to obtain more accurate results. From reference [11], the mechanical properties of aluminum foams with high porosity $(\mathrm{Pr}=85 \% \sim 90 \%)$ are similar, because their Young's modulus is basically the same, and the stress of yield platform is less than $1 \mathrm{MPa}$. Therefore, FCC pore structure model with porosity of $90 \%$ (Fig. 2) was used in this paper.

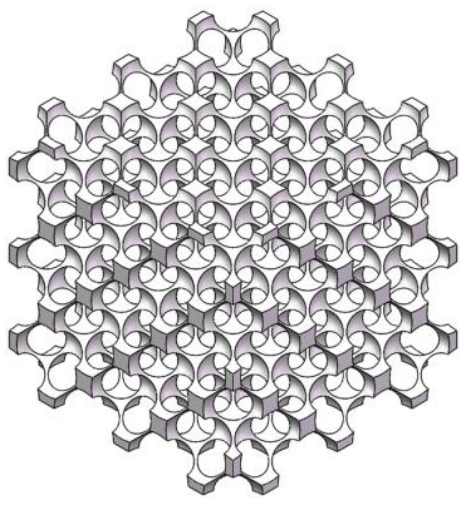

Figure 2. FCC pore structure model.

\subsection{Quasi-static compression simulation and results discussion}

\subsubsection{Setting of simulation parameters}

The quasi-static compression behavior of aluminum foam was simulated by using the Static Structure module of ANSYS Workbench. In the simulation, aluminum (ALUMINUM ALLOY) in the ANSYS material library was selected as the basic material, and the specific parameters of aluminum material were determined by referring to the parameters of ANSYS and other data. The specific parameters were as follows: Young's modulus was $71 \mathrm{GPa}$, Poisson's ratio was 0.33 , bulk modulus was 69.61GPa, and shear modulus was $26.69 \mathrm{GPa}$. The basic stress-strain relationship of aluminum is bilinear isotropic hardening (BISO). The yield point and the tangent modulus were set as $2.8 \mathrm{MPa}$ and $500 \mathrm{MPa}$ respectively [10].

\subsubsection{Meshing and setting of initial boundary conditions}

The Aggressive Mechanical option for large deformation simulation was used for the whole mesh, and Mesh Morphing was activated, which allows geometric adjustment of meshes under large deformation. The mesh type was the default ten-node tetrahedron of the system platform, and the cell size was defined as $0.1 \mathrm{~mm}$. Fig. 3 (a) shows the overall mesh generation effect of the model.

Fig. 3 (b) shows the setting of initial boundary conditions. Fixed Support was set at the lower end face of the lower die, and displacement was set at the upper end face of the upper die with a value of $-24 \mathrm{~mm}$. (a)

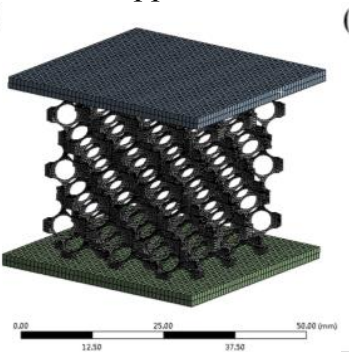

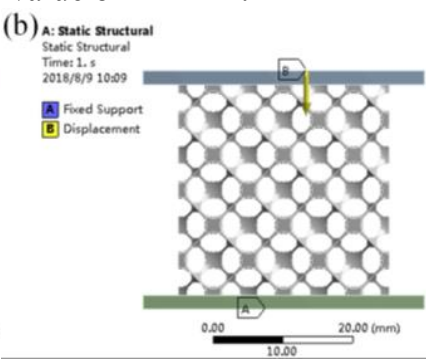

Figure 3. (a) mesh of the FCC model; (b) boundary and initial conditions.

\subsubsection{Discussion of simulation results}

Fig. 4 shows that there is no obvious nonlinear buckling deformation in the quasi-static compression process, and the forces acting on the wall and the beam of the face-centered cubic cavity structure are basically the same. There is a small stress concentration phenomenon on where the foam aluminum model contacts with the upper and lower pressure plates. It shows that the foam aluminum model with face-centered cubic cavity structure had uniform stress distribution during quasistatic compression, and the stress of the die can be well dispersed, which indicates that the foam aluminum model has good performance characteristics. 


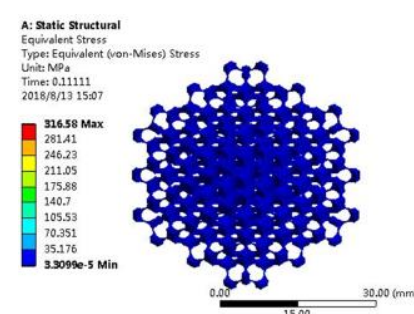

Strain

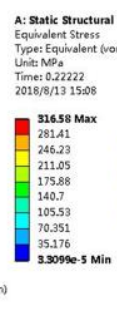

0.1

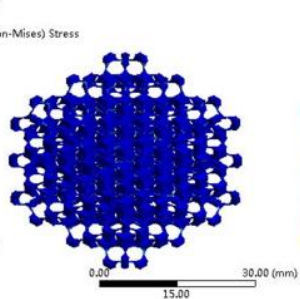

0.2

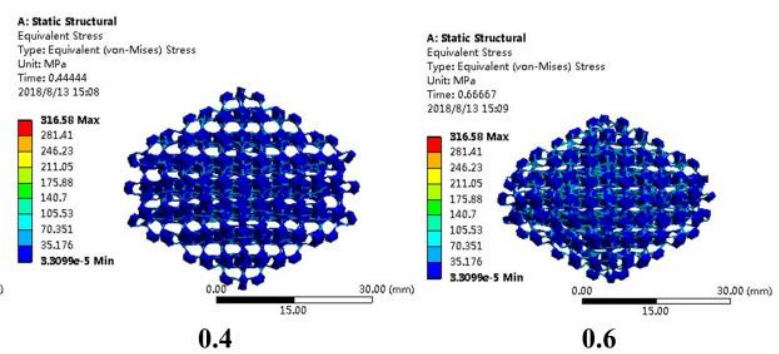

0.4
0.6

Figure 4. Von-Mises stress cloud of Al-foam model (FCC) with different strain under.

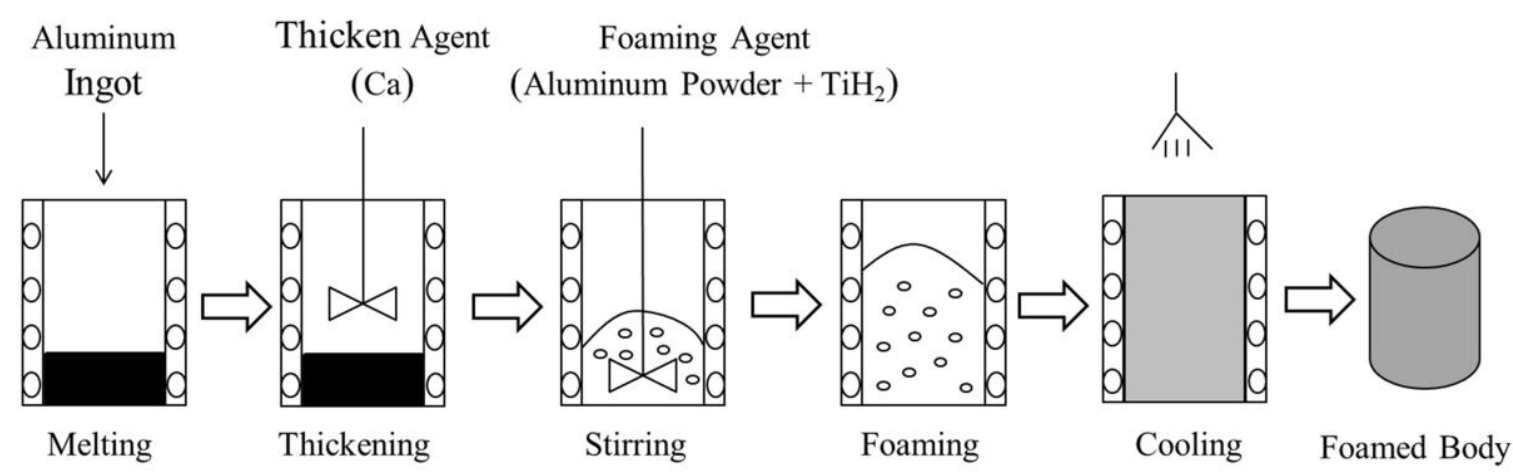

Figure 5. Production flow chart of aluminum foam.

\section{Materials and method}

\subsection{Preparation of aluminum foam body}

In this paper, closed-cell aluminum foam body was prepared by melt foaming method. After melting, thickening, stirring, foaming and cooling, the foamed body was produced finally. Among them, $\mathrm{Ca}$ particles with mass fraction of $2 \%$ were used as thicken agent, and mixed foaming agent, which was composed of $800 \mathrm{~g}$ aluminum powder and $8 \mathrm{~g} \mathrm{TiH} 2$ and milled for 5 hours by planetary ball mill (QM-3SP2), was used as foaming agent. The specific preparation process [12] is shown in Fig. 5.

\subsection{Method}

To avoid size effect, samples for compression test were cut into the dimension of $25 \times 25 \times 25 \mathrm{~mm} 3$ using a wire electro-discharging machine (WEDM). As the density of foam increases from top to bottom, aluminum foam with high density at the bottom was chosen as the sample. the location illustration of sample selection is shown in Fig. 6. Quasi-static compression tests were implemented using a universal testing machine (WDW-3100) under a pressure head speed of $2 \mathrm{~mm} / \mathrm{min}$ up to a nominal strain of 0.8 . In order to avoid the uncertainty and anisotropy during the tests, at least three samples were tested and the average data was adopted for each parameter.

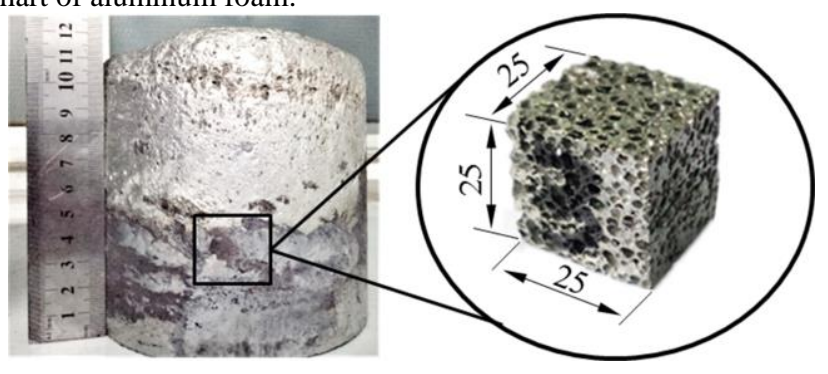

Figure 6. Location illustration of sample selection and sample size.

\section{Results and discussion}

\subsection{Compressive property}

Fig. 7 shows the stress-strain curves of aluminum foams with different densities after quasi-static compression tests. With the increase of pressure, aluminum foams have experienced three typical compression deformation stages. Under the compressive load, the aluminum foam first entered the elastic deformation stage. After the yield stress had been reached, the foamed aluminum began to enter the stress plateau stage where the deformation process was relatively stable and it stopped until the strain was 0.55 . Subsequently, the aluminum foam began to enter the densification stage, during which the compressive stress increased rapidly [13]. The whole compression deformation process is basically consistent with the finite element simulation of the compression process. 


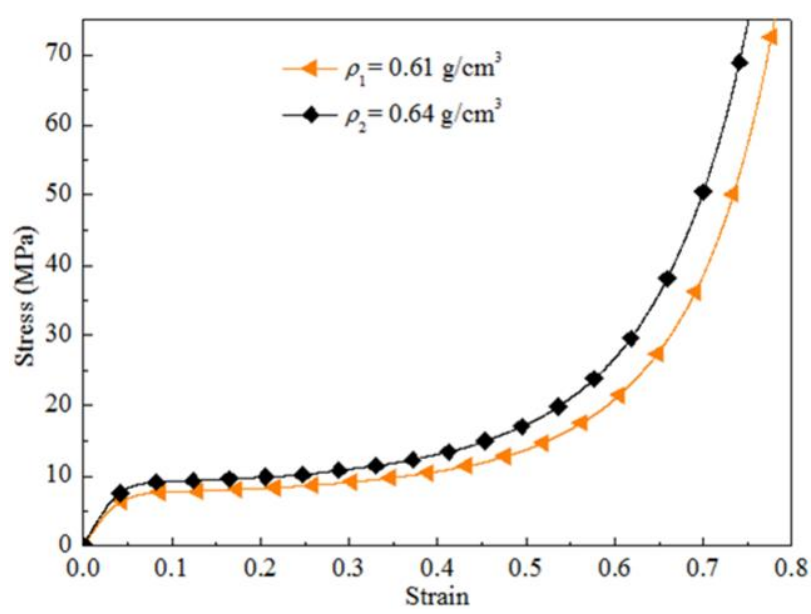

Figure 7. Stress-strain curves of aluminum foam compression with different strain rate.

In order to compare and characterize the test data of the aluminum foam with different densities, the peak stress $\left(\sigma_{y s}\right)$ and the plateau stress $\left(\sigma_{p l}\right)$ were selected as the main parameters of the compression property comparison. $\sigma_{p e}$ defined as the highest stress point in the elastic phase, $\sigma_{p l}$ defined as the average stress of strain between 0.2 0.4 [14] respectively. The above parameters were statistically calculated, and the obtained data were shown in Table 1. From the data of Table 1, we can see that the two kinds of aluminum foam have good compression properties. However, the yielding stress $\left(\sigma_{y s}\right)$ and plateau stress $\left(\sigma_{p l}\right)$ of aluminum foam with density of $0.64 \mathrm{~g} / \mathrm{cm}^{3}$ are 1.45 $\mathrm{MPa}$ and $1.89 \mathrm{MPa}$ higher than those of aluminum foam with density of $0.61 \mathrm{~g} / \mathrm{cm}^{3}$, respectively. It can be seen that the compressive properties of aluminum foam improve with the increase of density.

Table 1. Formatting sections, subsections and subsubsections.

\begin{tabular}{|c|c|c|}
\hline \multirow{2}{*}{$\begin{array}{c}\text { Density } \\
\left(\mathrm{g} / \mathrm{cm}^{3}\right)\end{array}$} & \multicolumn{2}{|c|}{ Stress (MPa) } \\
\cline { 2 - 3 } & $\sigma_{y s}$ & $\sigma_{p l}$ \\
\hline 0.61 & 6.81 & 9.22 \\
\hline 0.64 & 8.26 & 11.11 \\
\hline
\end{tabular}

\subsection{Energy Absorption Property}

Energy absorption capacity $\left(W_{E A}\right)$, and the specific energy absorption $\left(W_{S E A}\right)$ for weight sensitive applications were applied to characterize the energy absorption property of the materials [15], defined as:

$$
\begin{gathered}
W_{E A}=\int_{0}^{\varepsilon} \sigma(\varepsilon) d \varepsilon \\
W_{S E A}=\frac{W_{E A}}{\rho}
\end{gathered}
$$

Where $\varepsilon$ is the strain, $\sigma(\varepsilon)$ is the stress at the strain, $\rho$ is the density of the sample. $W_{E A}$ and $W_{S E A}$ versus compressive strain curves were plotted in Fig. 8.
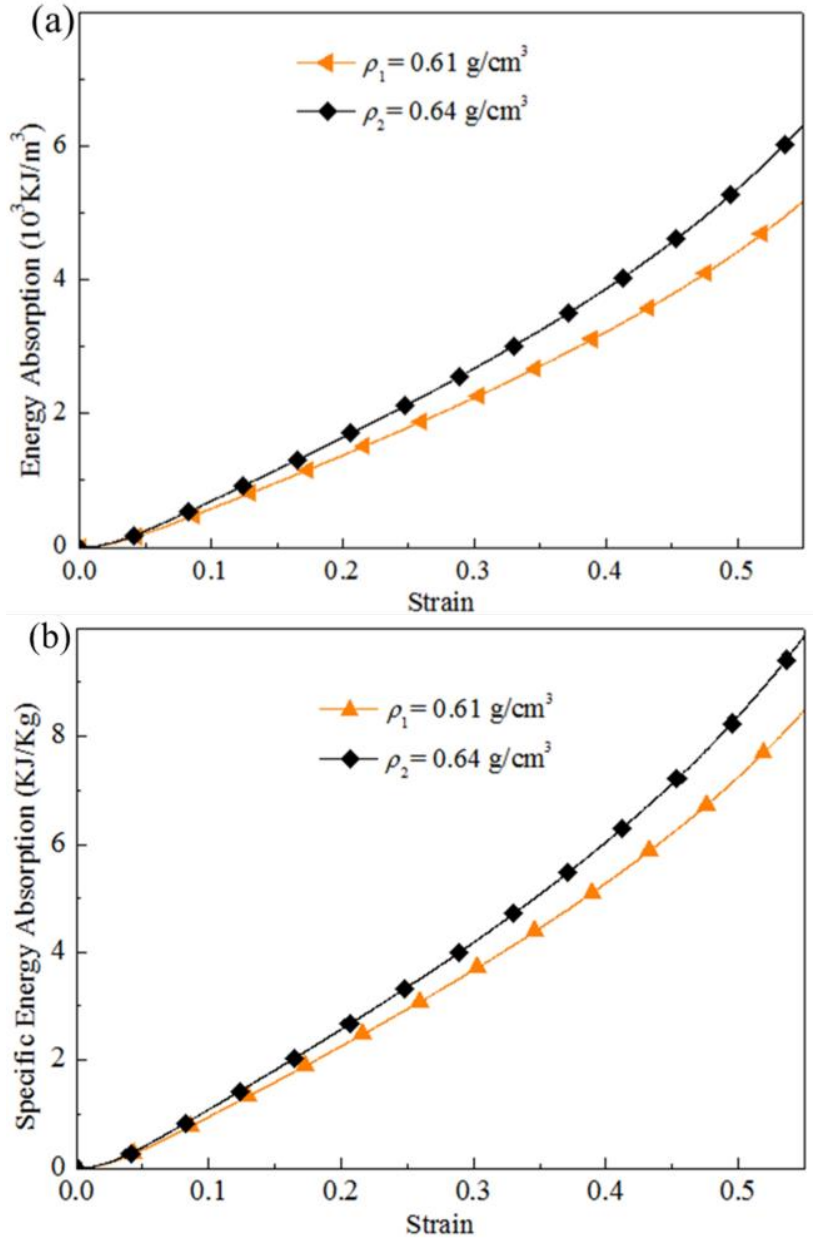

Figure 8. (a) Energy absorption, and (b) specific energy absorption curves of aluminum foam.

As can be seen from Fig. 8, parameters WEA and WSEA increase with the increase of compressive strain, and the slope of the curves increase gradually during the densification stage. The energy absorption capacity (WEA) of aluminum foams with densities of $0.61 \mathrm{~g} / \mathrm{cm}^{3}$ and $0.64 \mathrm{~g} / \mathrm{cm}^{3}$ were $5.18 \times 10^{3} \mathrm{KJ} / \mathrm{m}^{3}$ and $6.31 \times 10^{3} \mathrm{KJ} / \mathrm{m}^{3}$ respectively, and the $W_{S E A}$ values were $8.49 \mathrm{KJ} / \mathrm{Kg}$ and $9.87 \mathrm{KJ} / \mathrm{Kg}$ respectively. For these two values, the differences between aluminum foams with densities of $0.61 \mathrm{~g} / \mathrm{cm}^{3}$ and $0.64 \mathrm{~g} / \mathrm{cm}^{3}$ are about 1.5 . Hence, the energy absorption performance of aluminum foam is stable in a density range. When aluminum foam is applied to the shock absorber of spent fuel transport cask, the material can be filled into the impact limiter according to the density to obtain the required energy absorption performance requirements.

\section{Conclusion}

According to the mechanism of filler material for impact limiter of spent fuel transport cask, aluminum foam was selected and prepared by melt foaming method as filler material. The results of finite element simulation and quasi-static compression experiments show that aluminum foam has better compressive performance and overall energy absorption than traditional filler materials. The yield stress $\left(\sigma_{y s}\right)$ and plateau stress $\left(\sigma_{p l}\right)$ of aluminum 
foam with density of $0.64 \mathrm{~g} / \mathrm{cm}^{3}$ can reach $8.26 \mathrm{MPa}$ and $11.11 \mathrm{MPa}$ respectively, and the energy absorption capacity $\left(W_{E A}\right)$ and unit energy absorption capacity $\left(W_{S E A}\right)$ can reach $6.31 \times 10^{3} \mathrm{KJ} / \mathrm{m}^{3}$ and $9.87 \mathrm{KJ} / \mathrm{Kg}$ respectively, and the difference between the foam with density of $0.61 \mathrm{~g} / \mathrm{cm}^{3}$ and its various properties is very small.

It can be concluded that the aluminum foam in a certain density range has roughly the same performance, which reflects the stability of its performance more easily, and can be used for impact limiter installed on spent fuel transport cask more convenient.

\section{Acknowledgment}

This work was supported by the Natural Science Foundation of Shandong Province under Grant [number ZR2018MEM006]

\section{References}

1. G-S You, W-M Choung, J-H Ku, et.al. NUCL ENG TECHNOL, 41, 859-866 (2009)

2. Y Zhou, M You and Y Zhang, China Nuclear Science and Technology Report, 315-325 (1993)

3. IAEA, Regulations for the Safe Transport of Radioactive Material, Standard No. TS-R-1 (2009)

4. AQSIQ and SAC, Regulations for the Safe Transport of Radioactive Material, Standard No. GB11806-2004 (2014)

5. Silva AD, Kyriakides S. INT J SOLIDS STRUCT.; 44, 685-717 (2007)

6. Choi W-S, Seo K-S. NUCL ENG DES.240, 92532 (2010)

7. Zhang X, Jia G, and Huang $\mathrm{H}$, Chinese $\mathrm{J}$ Aeronautics, 24, 734 (2011)

8. Siegkas P, Tagariell V, and Petrinic N, Procedia Mater Sci, 4, 212 (2014)

9. X Zhu, S Ai, D Fang, B Liu, and X Lu, Computational Materials Science, 82, 451-456 (2014)

10. Z Hu, A Ma, D Yang, J Chen, and J Jiang, Materials Review, 29, 124-131 (2015)

11. T Mukai, T Miyoshi, S Nakano, H Somekawa, and K Higashi, 54, 533-537 (2006)

12. Y An, S Yang, Wu H, E Zhao, Z Wang, MATER DESIGN, 134, 44-53 (2017)

13. Y An, S Yang, E Zhao, Z Wang, COMPOS STRUCT, 178, 288-296 (2017)

14. Institution BS. Mechanical testing of metalsDuctility testing-Compression test for porous and cellular metals. 2011

15. LL Yan, ZY Zhao, B Han, TJ Lu and BH Lu, Materials Letters, 70-73 (2018). 